\title{
The ethics in qualitative health research: special considerations
}

\author{
A ética na pesquisa qualitativa em saúde: considerações especiais
}

Elizabeth Peter ${ }^{1}$

${ }^{1}$ Joint Centre for Bioethics, Lawrence S. Bloomberg Faculty of Nursing,

University of Toronto. Suite 130-155 College St. M5T

$1 \mathrm{P} 8$ Toronto ON Canada. elizabeth.peter@utoronto.ca

\begin{abstract}
A sound knowledge of the nature of qualitative research, along with an appreciation of some special ethical considerations, is needed for rigorous reviews to be conducted. The overall character of qualitative research is described with an emphasis on the tendency of qualitative researchers to explore sensitive topics using theoretically informed methods. A number of specific features of qualitative that require additional ethical attention and awareness are also examined including the following: 1) participants are frequently quite vulnerable and require protection because the data collection methods, such as indepth interviews, can delve into personally and politically charged matters; 2) naturalistic observation can raise concerns regarding privacy and consent; 3) the potential for the identifiability of the results of this research may require extra efforts to maintain confidentiality. Ultimately, Reseach Ethics Committee members must be knowledgeable about qualitative approaches to be able to assess the potential harms and benefits in a protocol carefully. Without this knowledge gaining ethics approval can be overly difficult for researchers and the best practices for protecting human participants can be overlooked.
\end{abstract}

Key words Ethics, Reseach Ethics, Qualitative research
Resumo O caráter geral da pesquisa qualitativa é descrito com ênfase na tendência de pesquisadores qualitativos para explorar temas sensiveis, utilizando métodos teoricamente informados. Algumas características específicas de pesquisa qualitativa que requerem consciência e atenção ética adicional também são examinadas, incluindo as seguintes: 1) frequentemente os participantes são bastante vulneráveis e necessitam de proteção porque os métodos de coleta de dados, tais como entrevistas em profundidade, podem levar a uma profunda análise de questões repletas de aspectos pessoais e políticos; 2) a observação naturalística pode levantar questões específicas em matéria de privacidade e consentimento; 3) o potencial de que os resultados da pesquisa possibilitem a identificação dos participantes exige esforços adicionais para proteger a privacidade deles. Em última análise, os membros dos Comitês de Ética em Pesquisa (CEP) devem conhecer as abordagens qualitativas para avaliar cuidadosamente os potenciais danos e benefícios em um protocolo. Sem esse conhecimento, a aprovação ética pode ser excessivamente difícil para os pesquisadores e as melhores práticas para proteger os participantes podem ser negligenciadas.

Palavras-chave Ética, Ética em pesquisa, Pesquisa qualitativa 
Qualitative research, particularly those studies using methods drawing from the social sciences and humanities, has become more common in health research as the recognition that interdisciplinary approaches have the potential to provide additional understanding to complex health problems has grown, at least in principle. Unfortunately, qualitative methods are not always understood and respected by all researchers. Many biomedical and clinical researchers believe that qualitative research is not legitimate science because it tends not to include an intervention that has been performed in a controlled environment or with a randomized sample that would allow causal or correlational relationships to be established or the potential for reproducibility ${ }^{1}$. While this bias toward qualitative research is certainly not universal, it is important to be aware of it because it can carry over into the ethical review of qualitative protocols given that Research Ethics Committees (RECs) tend to have a biomedical and clinical researchers sitting on them. Therefore, a sound knowledge of the nature of qualitative work, along with an appreciation of some special ethical considerations, is needed for rigorous reviews to be conducted.

While qualitative research is not inherently more risky, or less risky, than quantitative research, there are some features of qualitative research that RECs must be recognized to be able to review qualitative protocols effectively. Specifically, RECs must understand the overall character of qualitative research especially the tendency of qualitative researchers to explore sensitive topics using theoretically informed methods. A number of specific features of qualitative research that require additional ethical attention and awareness also need to be understood, including the following: 1) participants are frequently quite vulnerable and require protection because the data collection methods, such as in-depth interviews, can delve into personally and politically charged matters; 2) naturalistic observation can raise concerns regarding privacy and consent; 3 ) the potential for the identifiability of the results of this research may require extra efforts to maintain confidentiality. The articulation of these characteristics of qualitative research may stimulate discussion about common ethical concerns that exist across countries, including Canada and Brazil.

\section{The Nature of Qualitative Research}

Qualitative research embraces a full range of methodological and epistemological perspectivespositivism, postmodernism, phenomenology, and so on. Although a sharp demarcation between quantitative and qualitative research cannot be made, qualitative research tends to possess some common characteristics. Qualitative research is a situated activity that involves the researcher as a key instrument of data collection, not as an objective, authoritative, politically neutral observer. The data collected is richly descriptive and are often in the form of words and pictures with a frequent reliance on in-depth interviewing of research participants. The naturalistic approach of qualitative research also involves the field or setting itself being one source of data. Qualitative researchers observe not only the behaviors and activities of humans, but also the physical settings in which these activities take place ${ }^{2,3}$.

Qualitative researchers also tend to adopt an explicitly interpretative and theoretically mediated stance, with critical approaches from the social sciences and the humanities being especially common, such as historical materialism, critical theory, feminism and structuration ${ }^{4}$. This work tends to embrace an explicitly political dimension that challenges social practices and norms, particularly those related to biomedical approaches to health and disease. It also is often participatory in nature, aiming to give voice to marginalized populations and to critique dominant epistemological and normative ethical understandings, containing an element of self-critique that entails a critical posture with regard to qualitative inquiry itself ${ }^{5}$. As a result, RECs must be able to understand when examining the scientific merit of protocols that qualitative researchers are not striving to be 'objective' in the positivistic sense of the word, because they have deliberatively chosen a theoretical lens from an alternative epistemological paradigm. Standards to assess the rigour of such work are concerned more with theoretical coherence across the entire project than with matters such as sample size and generalizability. In addition, it is important for reviewers to appreciate the possible political harms and benefits of this research given its emphasis on identifying and disrupting power 
differences, not just those relating to physical or emotional well-being.

It is not uncommon for qualitative researchers to explore sensitive topics that examine social structures that create or perpetuate inequities involving participants who are in vulnerable circumstances $^{6}$. Lee and Renzetti's ${ }^{7}$ well-known description of four areas of research that tend to be classified as sensitive includes: "1) Research which delves into the private sphere or delves into some deeply personal experience; 2) Where the study is concerned with deviance or social control; 3 ) Where it impinges on the vested interests of powerful persons or the exercise of coercion or domination; 4) Where it deals with things sacred to those being studied which they do not wish profaned". These topics are sensitive because there can be harms associated with studying them that relate to emotional intrusiveness, shame, political upheaval and disrespect. Yet, these kinds of studies also can produce beneficial results that can help with the development of strategies to support vulnerable people, to give voice to people whose experiences and perspectives are generally hidden or marginalized, and to expose sources of oppression and corruption in society.

\section{In-depth Interviewing \& Protecting Vulnerability}

Qualitative researchers examine a range of phenomena often use in-depth interviews and focus groups to investigate the nature and meaning of very personal, even traumatic, events people have experienced, such as loss, abuse, marginalization, and life-threatening illnesses. Research that probes deeply into the personal experiences of participants can also be highly invasive, particularly psychologically and socially. Participants can be traumatized when they re-experience a painful event or disclose highly private or shameful material during an interview, although when interviews are conducted with skill and focus on participant resilience, participants also report benefits from this form of participation ${ }^{8}$. Researchers themselves can also be traumatized upon hearing and sharing in the painful memories and emotions of a research participant and may require supports to be built into the study for their needs too.

It is evident from the intense emotional responses that great care must be taken to minimize potential harms. Predicting harms may be somewhat difficult in qualitative research of this kind because of the uniqueness of individuals and the only partially controlled nature of in-depth interviewing. Responses to a paper-and-pencil questionnaire that is composed of scales can be more easily predicted than responses to an open-ended interview. Participants may reveal things in an interview that neither they nor the interviewer had intended to talk about, particularly when the role of the interviewer becomes blurred with that of a therapeutic one. Interviewers must be especially careful that they do not unintentionally manipulate participants to reveal more than they are comfortable doing ${ }^{9}$ and therefore, when establishing rapport with the participant, they must be clear regarding the nature of the research relationship and the participant's right to refuse to answer questions and withdraw from the research at any time.

A number of safeguards should be in place to minimize harm in a research protocol that involves vulnerable participants or sensitive topics. To avoid emotionally exhausting interviewers and participants the timing of interviews regarding sensitive topics needs to be taken into account. It is important to consider the recentness of an intensely emotional life experience to avoid the initial phase of shock. Interviews should not be too long, but should have enough time available for participants to take breaks if needed and successive interviews should not be scheduled too closely together ${ }^{10}$. Follow-up counseling should also be pre-arranged for participants needing ongoing support. Interviewers should be experienced in working with people in sensitive situations and should have professional supports of their own so that they have the opportunity for debriefing and mentoring.

RECs must understand that qualitative studies are often emergent in design, with data collection methods developing as a study unfolds, such as interview or focus group questions that are developed only after some data has been collected. Consequently, REC members must expect amendments and require experience and a moral imagination to be able to envision possible benefits and harms in research protocols. Time spent imagining the 'what if' is necessary and making effort to discover what the harms and benefits are from the perspective of the participants is essential $^{6}$. Unfortunately, however, there is not a strong evidence base available to ascertain what is like for people to participate in research ${ }^{11}$. Similarly, researchers are also required to demonstrate reflexivity when engaging in this type of research, i.e., they must be able to reflect on their values and the impact of the research on participants. 
They must also be prepared to seek ethical approval more than once if their project takes a significant unforeseeable turn that they did not predict.

\section{Naturalistic Observation \& Privacy}

Naturalistic observation can raise privacy concerns because it involves observing and, in some instances, interacting with participants in their own contexts. If privacy is understood to be "an individual's right to be free from intrusion and interference by others" ${ }^{\prime 6}$, naturalistic observation can intrude upon or interfere with participants' personal and sacred places, their physical privacy, along with their associational privacy.

Human geographers have articulated the significance of place to human life ${ }^{12,13}$. Places are much more than containers in which things happen, but are alive and matter ${ }^{13}$. Therefore, even in public places, naturalistic observation raises concerns regarding the privacy and dignity of those being observed. Those settings and activities that can be more potentially sensitive are those that are deemed sacred or private by those who occupy or take part in them. Some settings may possess great religious and cultural significance, such as places of worship, burial grounds, and places of historical importance. Cultural norms governing these settings and the activities that take place in them need to be respected. Moreover, it is important to recognize that what may be considered ordinary and public to the researcher or REC member may be sacred and private to the research participant.

Each protocol requires careful ethical consideration regarding the nature of the activities to be observed, the type of setting, and the means of recording observations. It is important to consider what reasonable expectations of privacy those in these settings or engaged in activities in them may have ${ }^{6}$. If privacy is expected, obtaining informed consent is generally necessary. Entering, viewing, and later portraying them in research reports requires ethical reflection and knowledge to avoid profaning them. A sound awareness of what observations could be made, and their possible sensitivity, needs to exist before data collection begins. Dialogue between the occupants of these settings and researchers could form the basis of such an understanding.

Naturalistic observation can also threaten physical privacy. For example, solitude is a type of physicial privacy ${ }^{14}$ that can be breeched if researchers are not aware of its importance. For example, people in instituitonal settings, such as hospitals, can easily be deprived of solitude, not only because of the presence of health care workers, but also researchers conducting observation. In addition, bodily modesty ${ }^{14}$, another form of physical privacy, must be respected. While receiving healthcare services, people often must expose themselves for care and examination. Nudity can become so commonplace that healthcare workers can easily forget to protect physical privacy, not remembering to cover people adequately. Here again, researchers who enter healthcare settings must pay attention to phyical privacy and recognize that people from some cultural and religious groups may have very strict norms regarding when it is appropriate to expose the body.

Participant observation, in which the researcher becomes involved in the activities of the participants, also poses potential ethical concerns particularly with regard to associational privacy. Associational privacy, which refers to the right of people to choose with whom they would like to be intimate, can be protected if researchers honour the participants' desire to share, or not share, specific experiences, such as those associated with childbirth, suffering, sickness, and dying with the reseacher ${ }^{14}$. It is also essential that the researcher not intrude upon the shared experiences that participants have chosen to only have with intimate others, such as family and friends. Ongoing consent with participants can be a way of ensuring that the privacy is protected in this regard.

\section{Thick Descriptions \& Confidentiality}

Unique concerns regarding confidentiality, also referred to informational privacy ${ }^{14}$, arise in qualitative research because of its production of thick descriptions of phenomena. Multiple sources of data are often used such as interviews, documents, photographs, observations and artifacts that can reveal the unique meanings that participants have brought to the research ${ }^{2}$. This data can be easily identifiable given its uniqueness, depth, and detail, making rigorous strategies to maintain confidentiality crucial. In some instances, researchers must refrain from collecting data that is not relevant to their research questions to avoid collecting more sensitive data than is needed. Much harm can come to participants if they are identified, including harms pertaining to health, reputation, employment, relationships, insurance, and criminality. The dissemination of results also requires that the data is aggregated 
and may also necessitate that the details of the data are carefully obscured so that no one is identified, particularly when there is a small sample of people experiencing a unique health-related problem or phenomenon.

There may be occasions, however, that it may be appropriate to identify participants with their explicit consent, such as times when participants would like to have their contributions recognized ${ }^{6}$. This situation may occur when participants create poems or artwork as forms of data. In participatory forms of research, in which the roles of researchers and participants are not distinct, openly acknowledging the identities of participants can be a method of appropriately recognizing the contributions of participants ${ }^{15}$.

Ensuring that participants are fully informed before consenting to be involved in the research can also pose some unique concerns regarding the requirement to disclose some forms of information. For example, participants must be informed that the information they provide cannot be kept confidential under all circumstances. The kind of information that participants might disclose needs to be considered in relation to the nature of the research and the interview questions being used. If there is a reasonable chance that participants will reveal intentions to harm themselves or others or reveal a history of abusing children, or legally relevant others, participants need to be clearly informed that the information they give could be shared with authorities, depending upon the laws of the region. Researchers must also inform participants under what circumstances they might be legally required to report criminal activity that participants might disclose.

\section{Conclusions}

Ultimately, REC members must be knowledgeable about qualitative approaches to be able to assess the potential harms and benefits in a protocol carefully. The data collection methods used by qualitative researchers often are quite open-ended and entail exposure to many sensitive and private matters that require awareness by REC members and researchers themselves. Although this paper has focused on the possible risks inherent in conducting qualitative research, it is essential to examine the overall balance of risks and benefits in any study. The many possible benefits of qualitative research generally outweigh the risks, if these risks are appropriately mitigated.

Without the knowledge and awareness of the special ethical considerations of qualitative research, gaining ethics approval can be overly difficult for researchers and the best practices for protecting human participants can be overlooked. Researchers and society, in general, can best be served with a broader appreciation of the differences that can exist in knowledge production and the application of ethical standards. Too much emphasis has been placed on learning research methods, at least in a North American context, without attending to the philosophical roots and controversies surrounding various research traditions. More emphasis placed on understanding differences in epistemological orientations, i.e., methodologies as opposed to methods, in the training of researchers would likely not only increase the mutual respect among researchers, but would aid in the process of skillful and respectful ethical review. 


\section{References}

1. Albert M, Laberge S, Hodges BD. Boundary-work in the health research field: biomedical and clinician scientists' perceptions of social science research. Minerva 2009; 47(2):171-194.

2. Creswell JW. Qualitative inquiry \& research design: choosing among five approaches. Thousand Oaks: Sage; 2013.

3. Denzin NK, Lincoln YS. Introduction: the discipline and practice of qualitative research. In: Denzin NK, Lincoln YS, editors. The Sage Handbook of Qualitative Research. Thousand Oaks: Sage Publications; 2011. p. 1-32.

4. Prasad P. Crafting qualitative research: working in the postpositivist traditions. Armonk: ME Sharpe; 2005.

5. Centre for Critical Qualitative Research. What is critical qualitative health research? 2015. [cited 2015 June 4]. Available from: http://www.ccqhr.utoronto.ca/ what-is-critical-qualitative-research

6. Canadian Institutes of Health Research, Natural Sciences and Engineering Research Council of Canada, and Social Sciences and Humanities Research Council of Canada. Tri-Council policy statement: ethical conduct for research involving humans. Ottawa: Interagency Secretariat on Research Ethics; 2014.

7. Lee R, Renzetti CM. The problems of researching sensitive topics. Am Behav Sci 1990; 33(5):510-528.

8. Agllias K. Utilizing participants' strengths to reduce risk of harm in a study of family estrangement. Qual Health Res 2011;21(8):1136-1146.

9. Fontana A, Frey JH. The interview: From structured questions to negotiated text. In: Denzin NK, Lincoln YS, editors. Handbook of qualitative research. Thousand Oaks: Sage Publications; 2005. p. 645-672.
10. Cowles KV. Issues in qualitative research on sensitive topics. Western J Nurs Res 1988; 10(2):163-179.

11. Cox SM, McDonald M. Ethics is for human subjects too: participant perspectives on responsibility in health research. Soc Sci Med 2013; 98:224-231.

12. Andrews GJ. Co-creating health's lively, moving frontiers: Brief observations on the facets and possibilities of non-represenational theory. Health Place 2014; 30:165-170.

13. Kearns RA, Moon G. From medical to health geography: novelty, place and theory after a decade of change. Health Place 2002; 26(5):605-625.

14. Allen A. Privacy and Medicine. In: Zalta EN, editor. The Stanford Encyclopedia of Philosophy (Spring 2011 Edition). [cited 2015 June 8]. Available from: http://plato. stanford.edu/archives/spr2011/entries/privacy-medicine/

15. Khanlou N, Peter E. Participatory action research: considerations for ethical review. Soc Sci Med 2005; 60(10):2333-2340

Apresentado em 23/04/2015

Aprovado em 10/06/2015

Versão final apresentada em 12/06/2015 